\title{
SURFACE COMPOSITION AND OXYGEN CHEMISORPTION ON Ag-Pd ALIOYS
}

\section{F. GARBASSI}

Donegani Research Institute, I-28100 Novara, Italy

and

\section{G. PARRAVANO *}

Department of Chemical Engineering, University of Michigan, Ann Arbor, Michigan 48109, USA

Received 12 July 1977; manuscript received in final form 7 September 1977

Ag-Pd alloys prepared by room temperature coprecipitation from solutions of the corresponding nitrates have been subjected to surface analysis by Auger electron spectroscopy. Previous work on the adsorption of $\mathrm{O}_{2}$ on the same alloys showed that except for very high Pd concentration the adsorption heat was independent of alloy composition. On untreated and $\mathrm{Ar}$ ion sputtered alloys Pd enrichment in the surface layers was found, while on thermally annealled alloys $\left(<0.1\right.$ Torr or $1 \mathrm{~atm}$ of $\mathrm{H}_{2}$ or $\mathrm{O}_{2}$ ), surface segregation of Ag tonk place. This is the expected result from surface tension and/or atomic size considerations. The relation of these findings with the earlier data on the chemisorption heat of oxygen is discussed. The implications of these conclusions upon present models of metallic alloys is pointed out.

\section{Introduction}

Several years ago heats of oxygen chemisorption were measured on $\mathrm{Ag}-\mathrm{Pd}$ alloys which were prepared by room temperature coprecipitation from a solution of their nitrates [1]. Heats of oxygen chemisorption in the temperature range 500 $700 \mathrm{~K}$ were deduced from measurements of the reaction equilibrium: $\mathrm{H}_{2} \mathrm{O}(\mathrm{g}) \rightleftharpoons$ $\mathrm{H}_{2}(\mathrm{~g})+\mathrm{O}(\mathrm{s})(1)$, where $\mathrm{g}$ and $\mathrm{s}$ refer to gaseous and adsorbed phases respectively. Conditions were adjusted such that less than a monolayer of oxygen was chemisorbed by means of reaction equilibrium (1), the fraction of surface covered with adsorbed oxygen varying between $1 \times 10^{-4}$ to 0.7 . The experiments showed that the adsorption heat retained a value close to that corresponding to pure $\operatorname{Ag}(-54$ $\mathrm{kcal} /$ mole) as the bulk alloy composition changed from $1 \mathrm{wt} \%$ to $100 \mathrm{wt} \% \mathrm{Ag}$. The heat of adsorption for oxygen on pure $\mathrm{Pd}$ was found to be $-24.6 \mathrm{kcal} / \mathrm{mole}$. From these results it was inferred that, in contrast to $\mathrm{Pd}$, Ag figured preponderantly in the

* To whom correspondence about this paper should be directed. 
composition of the alloy surface. This suggestion was strengthened by the observation of the functional relationship between the adsorption equilibrium constant for reaction (1) and oxygen surface coverage: for the $\mathrm{Ag}-\mathrm{Pd}$ alloys and pure $\mathrm{Ag}$ the function decreased with increasing oxygen surface coverage, while it was independent of coverage for $\mathrm{Pd}$.

It may also be argued that the similarity of the behavior of oxygen adsorption between alloys and pure Ag resulted from the details of the adsorption itself and not by surface enrichment of Ag. This contention may be justified by the relatively large difference in adsorption heat between the two metals, and by the assumption that the electronic properties of $\mathrm{Ag}$, which contribute to the $\mathrm{Ag}-\mathrm{O}$ binding energy, are not substantially modified by the presence of Pd. According to this suggestion $\mathrm{Pd}$ acted simply as a diluent for Ag. There was much interest in the resolution of the problem for the understanding of the surface reactivity of these alloys but because of the difficulty in performing an independent analysis of surface composition, the matter could not be resolved at that time.

By means of Auger spectroscopy it is now possible to determine the surface composition of these alloys and to resolve between the two alternatives. Presently, we have subjected the same alloy samples which were employed in the original adsorption-equilibrium reaction (1) to Auger analysis and, consequently, provided for a more definitive interpretation of the earlier experiments.

\section{Experimental}

Details on alloy preparation and characterization may be found in earlier publications $[1,2]$. Briefly, aliquots of chloride free $\mathrm{Ag}$ and $\mathrm{Pd}$ nitrates were dissolved in distilled water. Concentrated $\mathrm{HNO}_{3}$, saturated with $\mathrm{KNO}_{3}$, was added. The solution was cooled to $0^{\circ} \mathrm{C}$ and while stirring vigorously, $\mathrm{HCHO}$ and $\mathrm{NaOH}$ were added to a constant excess. The precipitate was decanted, washed and extracted in a Soxhlet extractor for $24 \mathrm{~h}$, dried at $110^{\circ} \mathrm{C}$. Clear separation of the $\alpha_{1}-\alpha_{2} \mathrm{X}$-ray diffraction lines were obtained, thus permitting an accurate computation of the lattice constant [3]. The fact that Vegard's law was closely followed was taken as an indication of alloy formation [1]. Electron microscopic examination of $\Lambda \mathrm{g}$ rich alloys showed extensive coalescence of the particles and a large amount of dendritic morphology with considerable internal structure (fig. 1) while Pd rich alloys appeared as a more compact, cellular aggregation of smaller crystallites (fig. 2). The morphology-composition interdependence of this alloy system was noted earlier on films evaporated on Pyrex glass [4]. The effect was correlated with the large difference in melting point of the metals.

Auger analysis was carried out with standard equipment (Physical Electronics Mod 540) employing a cylindrical mirror analyzer. Alloy samples were "supported" on In metal (99.999\%) [5]. The experimental conditions were as follows: operating pressure $1.3 \times 10^{-9}$ Torr, incident electron beam energy $3 \mathrm{keV}$, beam current 


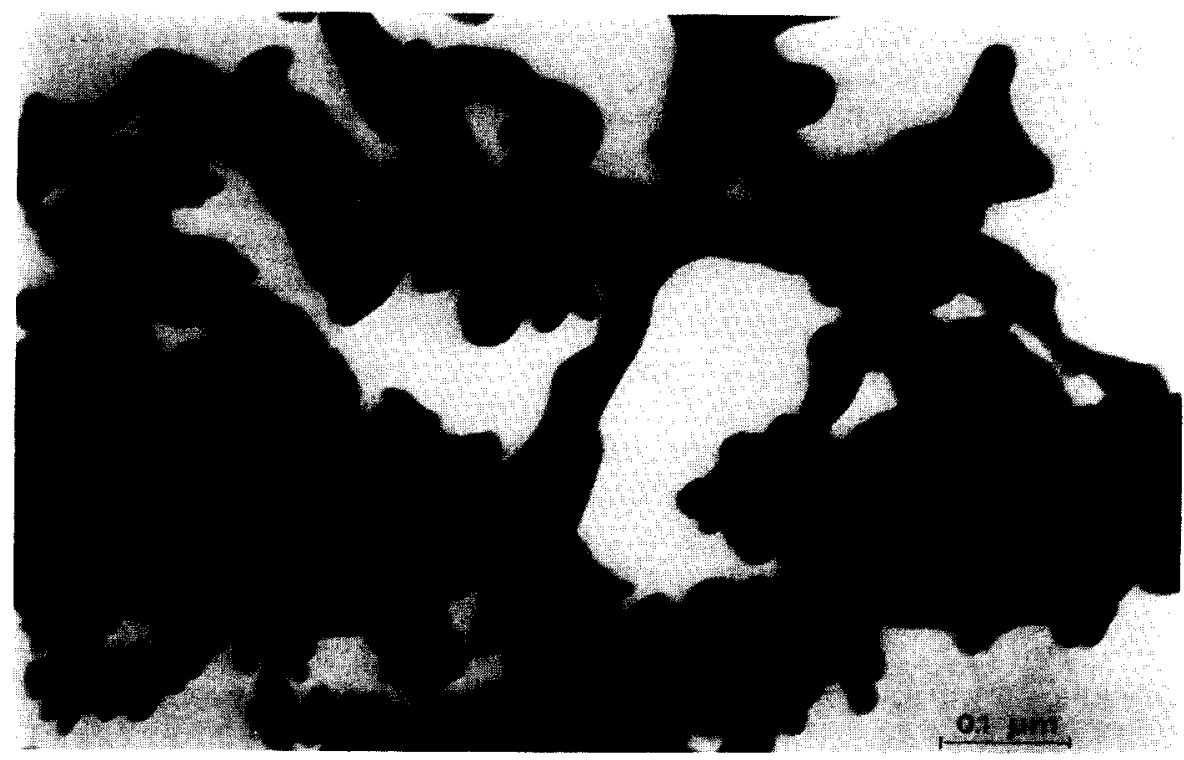

Fig. 1. Electron micrograph of $\mathrm{Ag}-\mathrm{Pd}$ alloy, $70 \mathrm{at} \% \mathrm{Ag}$.

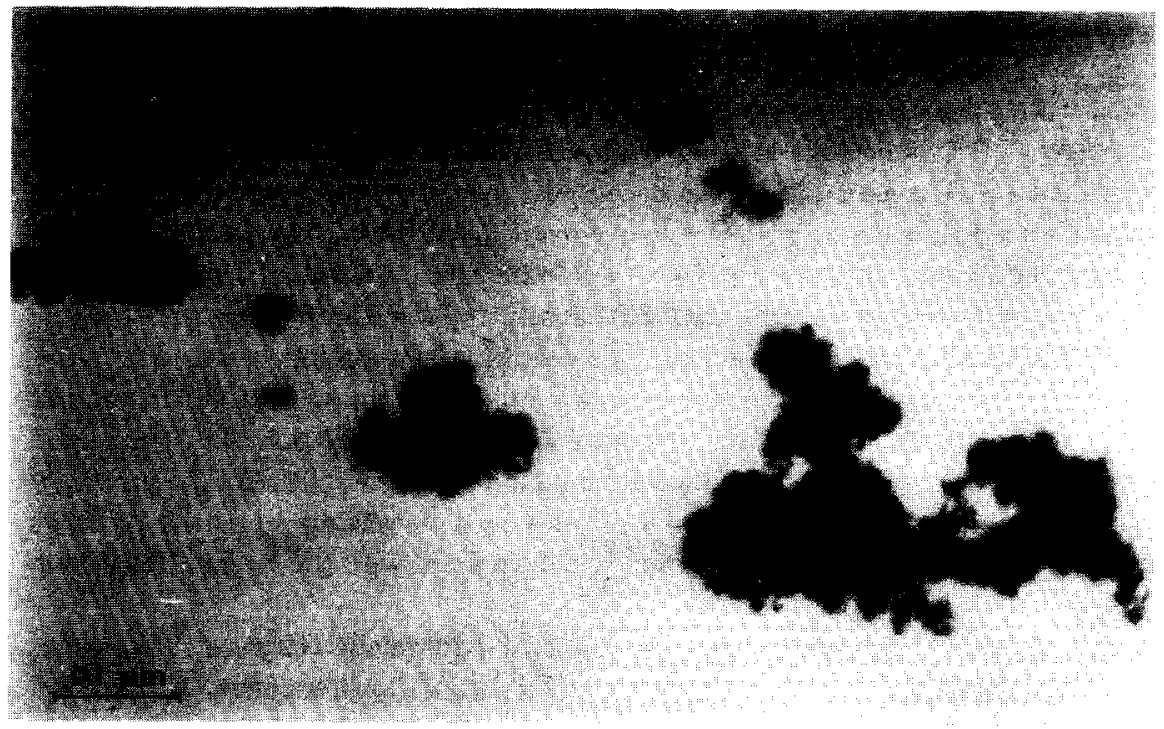

Fig. 2. Electron micrograph of $\mathrm{Ag}-\mathrm{Pd}$ alloy, $10 \mathrm{at} \% \mathrm{Ag}$. 
$50 \mu \mathrm{A}$, peak-to-peak modulation $3 \mathrm{~V}$, time constant $0.001 \mathrm{sec}$, and normal incidence of the primary beam. Compositions, $\mathrm{C}_{x}$ (\% atom fraction), were calculated by means of the equation [6]:

$C_{x}=\frac{H_{x} / f_{x}}{\left(H_{x} / f_{x}\right)+\left(H_{y} / f_{y}\right)} \times 100$,

where $x, y$ correspond to $\mathrm{Ag}$ and $\mathrm{Pd}$ respectively, $H$ is the Auger peak height, $f$ the sensitivity factor. The validity of eq. (2) rests on the assumption that peak intensity is proportional to the molar fraction of a given alloy component. For the $\mathrm{Pd}$. $\mathrm{Ag}$ system this assumption was found to be valid [7,8]. The $\mathrm{M}_{5} \mathrm{~N}_{4,5} \mathrm{~N}_{4,5}$ transitions of $\mathrm{Pd}$ at $300 \mathrm{eV}$ and that of $\mathrm{Ag}$ at $351-356 \mathrm{eV}$ and sensitivity factors of 1 and 1.4, respectively, were employed [9]. Their relative amplitude could be reproduced to better than $\pm 3 \%$. No overlapping of Auger peaks of the alloy components occurred. Each alloy was analyzed at various locations; variation in composition was found to be within \pm 1 at $\%$. Considering the reported Auger sampling depth of $\sim 8 \AA$ for $\mathrm{Ag}$, $350 \mathrm{eV}$ [10], we estimate about a similar sampling depth for the $\mathrm{Ag}-\mathrm{Pd}$ alloys.

\section{Results}

The results obtained are reported in fig. 3. All alloy samples displayed a surface richer in $\mathrm{Pd}$ than their bulk. There was an almost constant compositional difference between surface and bulk for alloys with $\mathrm{Ag}$ content down to 37at\%. The only detectable surface impurity was found to be carbon ( $\sim 5 \%)$ whose level, however, did not vary appreciably among the alloys and as a result of the various gas and thermal treatments. A few sputtering experiments were carried out using Ar ions,

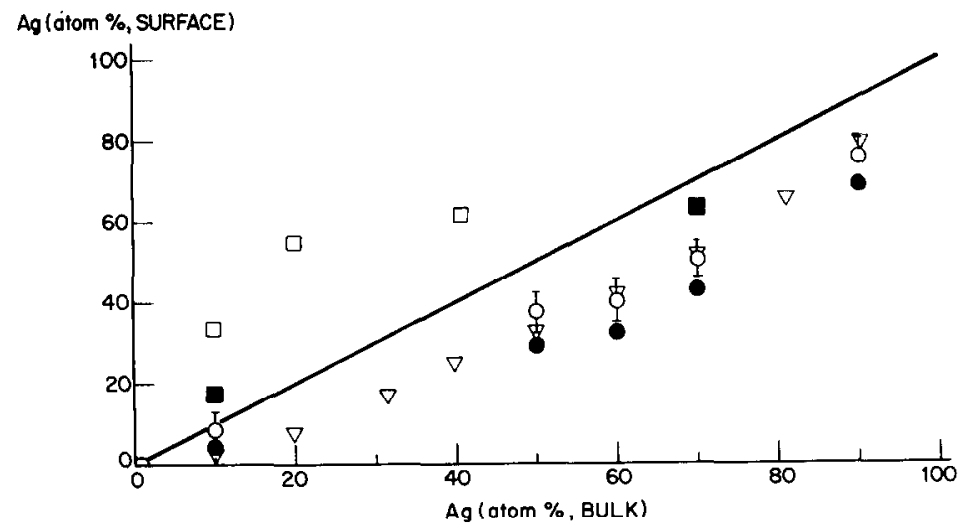

Fig. 3. Surface versus bulk composition of $\mathrm{Ag}-\mathrm{Pd}$ alloys; (O) this work, no pretreatment; (•) this work, $10 \mathrm{~min}$ sputtering; ( $)$ this work, $8 \mathrm{~h}, \mathrm{O}_{2}, 1 \mathrm{~atm}$; (จ) from ref. [8]; (व) from ref. [11]. 
Table 1

Effect of sputtering on surface composition of $\mathrm{Ag}-\mathrm{Pd}$ alloys, $\mathrm{Ar}$ ions, $950 \mathrm{eV}, 10 \mu \mathrm{A}$, $5 \times 10^{-5}$ Torr, $10 \mathrm{~min}$

\begin{tabular}{lll}
\hline $\begin{array}{l}\text { Bulk compo- } \\
\text { sition (Ag at\%) }\end{array}$ & Treatment & $\begin{array}{l}\text { Surface compo- } \\
\text { sition (Ag at\%) }\end{array}$ \\
\hline 90 & None & 75 \\
70 & Sputtering & 70 \\
& None & 50 \\
60 & Sputtering & 47 \\
50 & None & 40 \\
& Sputtering & 35 \\
10 & None & 37 \\
& Sputtering & 29 \\
& None & 8 \\
\hline
\end{tabular}

$950 \mathrm{eV}, 10 \mu \mathrm{A}, 5 \times 10^{-5}$ Torr, 2 and $10 \mathrm{~min}$ periods. Subsequent to sputtering the surface $\mathrm{Ag}$ content decreased (table 1). This is most likely attributable to the higher sputtering rate of $\mathrm{Ag}$ in relation to that of $\mathrm{Pd}[8]$.

The present results are consistent with previous Auger observations on polished $\mathrm{Ag}-\mathrm{Pd}$ alloy tablets which had undergone sputtering experiments [8] (fig. 3), while the surface of epitaxially grown $\mathrm{Ag}-\mathrm{Pd}$ alloy films $(<1000 \AA$ thick) showed no enrichnent in either metal [7]. On vacuum fractured alloys, the surface composition reproduced very closely that of the bulk [8]. On Ag-Pd particles embedded on a support of an undisclosed nature surface $\mathrm{Ag}$ enrichment was detected [11] (fig. 3).

lable 2

Effect of thermal anneal and gas atmosphere on surface composition of Ag-Pd alloys

\begin{tabular}{lll}
\hline $\begin{array}{l}\text { Bulk compo- } \\
\text { sition }(\mathrm{Ag} \mathrm{at} \%)\end{array}$ & Treatment & $\begin{array}{l}\text { Surface compo- } \\
\text { sition }(\mathrm{Ag} \text { at } \%)\end{array}$ \\
\hline 70 & & 50 \\
& None & 73 \\
& $\mathrm{H}_{2}, 1 \mathrm{~atm}, 400^{\circ} \mathrm{C}, 3 \mathrm{~h}$ & 64 \\
& $\mathrm{O}_{2}, 1 \mathrm{~atm}, 300^{\circ} \mathrm{C}, 8 \mathrm{~h}$ & 67 \\
& Air, $0.5 \mathrm{Torr}, 300^{\circ} \mathrm{C}, 7 \mathrm{~h}$ & 37 \\
50 & & 50 \\
& None & 53 \\
& $\mathrm{H}_{2}, 1 \mathrm{~atm}, 400^{\circ} \mathrm{C}, 3 \mathrm{~h}$ & 9 \\
10 & Air, $0.5 \mathrm{Torr}, 300^{\circ} \mathrm{C}, 7 \mathrm{~h}$ & 17 \\
& None & \\
& $\mathrm{O}_{2}, 1 \mathrm{~atm}, 300^{\circ} \mathrm{C}, 8 \mathrm{~h}$ &
\end{tabular}


Because of the interest in investigating the effect of thermal anneal under different gas atmospheres on surface composition, experiments were carried out on alloys which had been annealed in $\mathrm{H}_{2}\left(400^{\circ} \mathrm{C}, 1 \mathrm{~atm}, 3 \mathrm{~h}\right)$, in $\mathrm{O}_{2}\left(300^{\circ} \mathrm{C}, 1 \mathrm{~atm}\right.$, $8 \mathrm{~h})$, and at low residual pressure $\left(300^{\circ} \mathrm{C}, 0.1\right.$ Torr, $\left.7 \mathrm{~h}\right)$. Cooling to room temperature was carried out in a gas atmosphere similar to that prevailing during the high temperature anneal. The results are collected in table 2.

\section{Discussion}

In the temperature range of interest $\mathrm{Ag}$ and $\mathrm{Pd}$ form a continuous series of disordered solid solutions [12]. Ag has a lower surface tension and a smaller atomic radius than $\mathrm{Pd}$. Consequently, it is to be expected that $\mathrm{Pd}$ atoms at the surface of $\mathrm{Ag}-\mathrm{Pd}$ alloys have a tendency to exchange with $\mathrm{Ag}$ atoms from the interior, leading to a surface enrichment of Ag. Quantitative predictions on the amount of enrichment are dependent upon various assumptions - possible role of short-range order [13] and/or of non-nearest neighbors interchange - which are difficult to define with precision. Experimental measurements of surface composition agree with this simple model. Using photoelectron emission [14] and $\mathrm{CO}$ adsorption [15] on alloy films, Ag enrichment was found, while the composition of surface (100) and (111) planes of epitaxially grown alloy films (250-1000 $\AA$ thick) was found by Auger spectroscopy to be similar to that of the bulk [7]. Thus, under some conditions size and/or surface tension effects may not be sufficient to produce preferential segregation of $\mathrm{Ag}$ at the surface. In the latter studies $\mathrm{Ag}$ enrichment was present in non equilibrated films only. Inspection of fig. 3 shows that in the present investigation, with the exception of the 1 and $10 \mathrm{Ag}$ at\% alloys, the latter were enriched in $\mathrm{Pd}$. This was a consequence of the preparation method employed and the resulting conditions of growth of alloy nuclei during precipitation. If the reduction rate of $\mathrm{Ag}\left(\mathrm{NO}_{3}\right)$ in solution was faster than that of $\mathrm{Pd}\left(\mathrm{NO}_{3}\right)_{2}$, local depletion of the $\mathrm{Ag}$ salt may have taken place, even under vigorous stirring, and an incresingly higher amount of Pd may be accumulated in layers closer to the surface. This effect may be supported by the observation that for low $\mathrm{Ag}$ content, the bulk composition was very nearly equal to the surface composition while Pd enrichment set in and increased with increasing $\mathrm{Ag}$ bulk content. At high $\mathrm{Ag}$, the excess over $\mathrm{Pd}$ was sufficient to overcome any local depletion which may have been generated by a faster precipitation rate (fig. 3). Further support for the existence of different precipitation conditions between alloys with low and high $\mathrm{Ag}$ content is derived from the observation of the drastically different morphology of the 10 and $70 \mathrm{Ag}$ at $\%$ alloys (figs. 1 and 2). Surface composition and morphology of the alloys were controlled by local conditions during precipitation.

Two important conclusions may be drawn from the experiments on thermal anneal, namely: (a) surface $\mathrm{Ag}$ segregation increased, irrespective of the conditions prevailing in the surrounding gas phase, (b) at the relatively high temperature of 
$400^{\circ} \mathrm{C}\left(\sim 0.55 T_{\mathrm{m}}\right.$ for $\left.\mathrm{Ag}\right)$ surface - bulk equilibrium was not achieved even after $3 \mathrm{~h}$ treatment. In contrast to this relatively slow equilibration, on alloy films equilibrium was found to set in rapidly at $250^{\circ} \mathrm{C}$ [4]. Sputtering with Ar ions was found to increase the surface content in $\mathrm{Pd}$. This is an expected result in view of the faster sputtering rate of $\mathrm{Ag}[8]$.

The results of the earlier study on the heats of adsorption of oxygen have been replotted using the surface compositions observed in the present work (fig. 4). It should be noted that some caution must be exercised in comparing a typical monolayer effect (chemisorption) to a multilayer phenomenon (Auger electron emission). In fact, it may happen that by converting the Auger signals to atomic layer compositions, through a knowledge of the electron attenuation length, differences in the first layer from the values averaged over the few lopmust layers may be found [16]. Assuming that these differences are not significant for the present alloys, some important conclusions may be drawn from the characteristic correlation shown in fig. 4 . It should be noted that surface compositions of the untreated alloys have been used in fig. 4 (instead of the $\mathrm{H}_{2}$ annealed used in the study of the reaction equilibrium (1) [1], since the $\mathrm{H}_{2}$ treatment did not produce a significant surface composition change (table 2). Fig. 4 shows that the value of the adsorption heat of oxygen is almost independent of the surface composition of the alloys and very near to that for pure $\mathrm{Ag}$. This observation, together with the realization that the alloy surface of all samples except the 1 and 10\% Ag alloys, contained Pd in excess to the equilibrium composition, indicates that the behavior represented in fig. 4 was the result of the nature of the adsorption itself and not of excess Ag segregation at the surface. This conclusion raises two questions regarding the electronic nature of (a) the $\mathrm{Ag}$-oxygen bond, and of (b) the $\mathrm{Ag}-\mathrm{Pd}$ alloys. Although a detailed analysis of both of these questions is not possible here, we shall endevour to indicate a few relevant points. Clearly the almost constant value of the oxygen adsorption heat on a surface containing large amounts of $\mathrm{Pd}$ cannot be easily reconciled with an alloy model which assumes that $\mathrm{Ag}$ and $\mathrm{Pd}$ form common bonds and

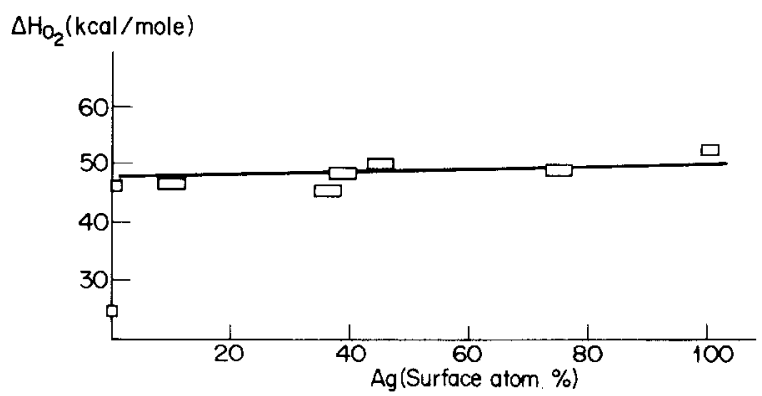

Fig. 4. Surface composition of $\mathrm{Ag}-\mathrm{Pd}$ alloys versus heat of $\mathrm{O}_{2}$ chemisorption, $\Delta \mathrm{H}_{\mathrm{O}_{2}}$ (from ref. [1]). 
that $\mathrm{Ag}$ s-electrons lead to filling of the $\mathrm{Pd} \mathrm{d}$-states until the $60 \mathrm{wt} \% \mathrm{Ag}$ composition is reached. Since oxygen- $\mathrm{Ag}$ bonding involves s-electrons from $\mathrm{Ag}$ and pelectrons from oxygen, it is difficult to visualize how with increasing $\mathrm{Ag}$ concentrations, the energy of the bond remains practically constant while the availability of selectrons increases. A different model for metallic alloys assumes that each component is well screened from the other and has the same electronic structure as the pure phase [17]. Additions of Pd simply dilute Ag leaving its adsorption characteristics unchanged and the overall adsorption behavior of the alloy is a superposition of those of the two metals. Because of the relatively large difference between $\mathrm{Ag}$ and $\mathrm{Pd}$ in the adsorption heat for oxygen, it is most likely that $\mathrm{Ag}$ atoms only were covered with oxygen. Thus, the present results are more consistent with this latter alloy model, even though it appears that some changes in the s-electron population of $\mathrm{Ag}$ upon alloying with Pd must be allowed for [18]. Other effects, including the possibility of formation of $\mathrm{Ag}$ surface clusters, sharing in the chemisorption bond and giving an adsorption heat essentially similar to that of $\mathrm{Ag}$, may also be invoked, but a realistic quantification of this idea is hard to achieve. The conclusion seems inescapable that dilution of $\mathrm{Ag}$ with $\mathrm{Pd}$ did not influence the chemisorption bond energy of $\mathrm{O}_{2}$ on $\mathrm{Ag}$; and one is essentially confronted with a dilution effect. Interestingly, a similar picture has emerged from studies on $\mathrm{CO}$ chemisorption on $\mathrm{Pd}$ and $\mathrm{Ag}-\mathrm{Pd}$ [19]. In this instance, the frequency of IR bands of CO adsorbed on Pd sites remained almost constant with varying alloy composition. Also, the activation energy for $\mathrm{CO}$ desorption was found to be insensitive to alloy composition. The Authors conclude for a decisive effect of Ag dilution upon the geometry of the $\mathrm{Pd}$ adsorption site, the latter being important for the various adsorption modes of $\mathrm{CO}$.

\section{Conclusions}

$\mathrm{Ag}-\mathrm{Pd}$ alloys, prepared by low temperature precipitation from solutions of the corresponding nitrate, follow closely Vegard's law, but show Pd enrichment at the surface in contrast with the $\mathrm{Ag}$ enrichment which may be expected from surface tension and/or atomic size considerations. It is suggested that the compositional inhomogeneity between surface and bulk is the result of nucleation and growth rate differences between $\mathrm{Pd}$ and $\mathrm{Ag}$. The thermodynamic affinity of $\mathrm{Ag}$ in oxygen chemisorption was not influenced by Pd alloying, which acted as an almost inert diluent to Ag. Interestingly, this behavior is reminiscent of that observed earlier in $\mathrm{CO}$ chemisorption, whose initial heat was found to be largely independent of alloy composition [7]. We conclude that electronic interactions responsible for metalmetal bonding in the alloy did not have a primary role in the metal-oxygen bonding at the surface.

Surface composition in the $\mathrm{Ag}-\mathrm{Pd}$ system is controlled by conditions employed in the preparation and treatment of the alloy. Depending upon the temperaturetime-atmosphere chosen, a surface enriched in either $\mathrm{Ag}$ or Pd may be obtained and retained even at moderate temperatures. 
Finally, oxygen chemisorption seems to indicate a surface whose structure and composition are controlled by a simple dilution of $\mathrm{Ag}$ atoms by $\mathrm{Pd}$ in a disordered fashion rather than by atomic ensembles of fixed composition and structure [20].

\section{Acknowledgment}

One of us (G.P.) wishes to acknowledge with thanks the financial support of the National Science Foundation through grant No. Eng 75-14193.

\section{References}

[1] M.H. Bortner and G. Parravano, in: Advances in Catalysis and Related Subjects, Vol. 9 (Academic Press, New York, 1957) p. 424.

[2] F. Hund and E. Tragner, Naturwissenschaften 39 (1952) 63.

[3] M. Straumanis and $\Lambda$. Ievins, Die Präzisionsbestimmung der Gitterconstanten nach Asymmetrischen Methode (Springer, Berlin, 1940).

[4] R.L. Moss and D.H. Thomas, J. Catalysis 8 (1967) 151.

[5] G.A. Theriault, T.L. Barry and M.J.B. Thomas, Anal. Chem. 47 (1975) 1492.

[6] P.W. Palmberg, Anal. Chem. 45 (1973) 549A.

[7] K. Christman and G. Ertl, Surface Sci. 33 (1972) 254.

[8] H.J. Mathieu and D. Landolt, Surface Sci. 53 (1975) 228.

[9] P.W. Palmberg, G.E. Riacli, R.E. Webes and N.C. M.Donald, Handbook of Auger Electron Spectroscopy (Physical Electronics Industries, 1972).

[10] P.W. Palmberg and T.N. Rhodin, J. Appl. Phys. 39 (1968) 2425.

[11] B.J. Wood and H. Wise, Surface Sci. 52 (1975) 151.

[12] M. Hansen, The Constitution of Binary Alloys (McGraw-Hill, New York, 1958);

J.N. Pratt, Trans. Paraday Soc. 56 (1960) 975;

R. Oriani and W.K. Murphy, Acta Met. 1 (1962) 879;

J.P. Chan and R. Hultgren, J. Chem. Thermodynamics 1 (1969) 45.

[13] R.W. Westerland and M.E. Nicholson, Acta Met. 14 (1966) 569.

[14] R. Bouwman, G.J.M. Lippits and W.M.H. Sachtler, J. Catalysis 25 (1972) 350.

[15] J.J. Stephan, P. L Franke and V. Ponec, J. Catalysis 44 (1976) 359.

[16] J.M. McDavid and S.C. Fain, Surface Sci. 52 (1975) 161

[17] N.D. Lang and H. Ehrenreich, Phys. Rev 168 (1968) 605.

[18] C. Norris and H.P. Myers, J. Phys. F1 (1971) 62;

E.A. Stern, Physics 1 (1965) 255.

[19] Y. Soma-Noto and W.M.H. Sachtler, J. Catalysis 32 (1974) 315.

[20] D.A. Dowden, in:Catalysis, Proc. 5th Intern. Congr. on Catalysis, Miami Beach, 1972, Ed. J.W. Hightower (North-Holland, Amsterdam, 1973) Vol. 1, p. 621. 